\title{
Albanians in Greece and the social meaning of ethnolectal features in L2 Greek
}

\author{
Rexhina Ndoci*
}

\begin{abstract}
Albanian migrants in Greece constitute the largest ethnic minority in the country, amounting to roughly $5 \%$ of the total population. The reception of these Albanian migrants has not been smooth and rather has been marked by "extreme xenophobic and racist discourse" (Archakis 2020:5) towards the members of the ethnic community. This discourse is also evident online where it often takes the form of internet memes which target Albanians and their L2 Greek (Ndoci 2021, forthcoming a). In this paper I investigate the social perception of the features of this Albanian L2 Greek through a matched guise experiment. My findings show that individuals who produce Albanian L2 features in their Greek are negatively stigmatized, either overtly or covertly, similarly to the way in which Albanian migrants have been stigmatized in the Greek context. This stigmatization seems to be exhibited both by members of the ethnic group itself and by members of the host community (i.e. Greeks). Moreover, the two groups appear to have differential awareness of the systems of ethnic, regional, and accented Greek that is the product of their experience with the varieties.
\end{abstract}

Keywords. social meaning; speech perception; ethnic varieties; migration; Albanian; Modern Greek

1. Introduction. The fall of the communist regime in Albania in the early 1990s was followed by a wave of "mass migration" of Albanians mainly towards their neighboring Greece and Italy (Mai \& Schwandner-Sievers 2003:940). As a result of this mass migration, Albanians now constitute approximately $5 \%$ of the population of Greece, half a million individuals or more than $50 \%$ of the population with a foreign citizenship in the country (Hellenic Statistical Authority 2014). In this paper I investigate the social meaning of Albanian ethnolectal features in the L2 Greek of these Albanian migrants which will be referred henceforth Albanian Greek.

Since their arrival, Albanians have been met with "extreme xenophobic and racist discourse" (Archakis 2020:5). They have been presented by the media as "cunning", "primitive", "untrustworthy", "dangerous" individuals, and "criminal[s]" (Lazaridis \& Wickens 1999:648). This public discourse has led to the creation of jokes about Albanians in the first two decades of their presence in Greece that were widely circulated and reproduced in the Greek context (cf. Archakis \& Tsakona 2021). With the widening and expansion of internet use in the country, the conversation shifted to the digital space and the jokes took the form of internet memes which largely reproduce the same stereotypes about Albanian migrants. At the same time, the content of the memes occasionally shows some resistance to the same stereotyping to which Albanians are subject (Ndoci 2021, forthcoming a).

Apart from offering a representation of Albanian migrants, internet memes also offer a glimpse into the features that constitute, or are assumed by the meme creators to constitute, an Albanian L2 variety of Standard Modern Greek (SMG). These features of Albanian Greek seem to be products of L1 imposition (i.e. imposition from Albanian) into the L2 (i.e. Greek). The

\footnotetext{
*Special thanks to Brian Joseph, Kathryn Campbell-Kibler, Donald Winford, and the members of the Changelings and SoMean discussion groups at the OSU Department of Linguistics for valuable help and comments throughout this project. All shortcomings remain my own. Author: Rexhina Ndoci, The Ohio State University (ndoci.1@osu.edu).
} 
most frequently occurring feature of Albanian Greek that internet memes contain is the substitution of the SMG palatal [c] and velar $[\mathrm{x}]^{1}$ voiceless fricatives by the velar plosive $[\mathrm{k}]$ in Albanian Greek suggesting that, at least for the meme creators, this is a salient feature of the variety (ibid.). In some of the memes, however, the SMG palatal fricative [c] is substituted in Albanian Greek by the voiceless palatal affricate [ $\widehat{\text { cç] }}$ indicating that some Albanians speakers are able to pick up on the difference between those two fricatives in SMG and to substitute them in Albanian Greek with different phones based on a process of phonological adaptation (ibid.). This finding raises questions that have to do with potential different degrees of Albanianness or Albanian Greek speech indexed by the two phones and the kinds of associations listeners make about speakers of Albanian Greek based on those two features. I attempt to answer those questions in the remainder of this paper.

In what follows, I describe a matched guise experiment that was designed and carried out to investigate the social meaning of the Albanian features (section 2), I present some major findings from the experiment (section 3), I offer some discussion of the findings, and then I draw some broader conclusions (section 4).

2. Methods. Based on the frequently occurring features of Albanian Greek found in memes, a matched guise experiment was designed in the form of an online survey to investigate the social perception of those features. Thus, the variables examined here are the palatal (ç) and velar (x) fricatives and their respective variants: the SMG [ç] and the Albanian Greek [k] and [ $\widehat{\mathrm{ccc}}]$ for the (ç) variable, and the SMG $[\mathrm{x}]$ and Albanian Greek $[\mathrm{k}]$ for the $(\mathrm{x})$ variable.

The survey participants heard, in a randomized order, a series of audio sentences in Greek produced by two men who are bilingual in Albanian and Greek. The listeners heard each sentence in its SMG and Albanian Greek versions. That is, for (ç), listeners heard a sentence once with the token produced with the SMG fricative [c] variant, once with the Albanian Greek

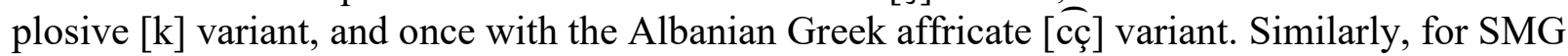
(x), listeners heard a sentence once with the token produced with the SMG fricative [x] variant, and once with the Albanian Greek plosive [k] variant. The target features were embedded in a set of words that are emblematic of Albanian Greek (e.g. 'knife') as well as a set of words that are not emblematic (e.g. 'hand') (for the effects of word emblematicity see Ndoci 2021, forthcoming b). After each audio stimulus, participants were asked to rate the talkers, on a scale from 1 (completely disagree) to 6 (completely agree), on the following set of talker-related traits:

- The talker sounds like a friendly person.

- The talker sounds like a likeable person.

- The talker sounds like a polite person.

- The talker sounds like a sensible person.

- The talker sounds like an aggressive person.

- The talker sounds like a person who curses.

- The talker sounds like a person who could be a criminal.

- The talker sounds like a person from a rural area.

- The talker sounds like a person from Albania.

Ethnically Albanian and ethnically Greek participants were sought through public postings in various social media platforms and mailing lists. As ethnically Albanian are identified here

${ }^{1}$ SMG [c] and [x] stand in allophonic variation where the former occurs in front of the front vowels [i], [e] and the semi-vowel [j], while the latter occurs in all other environments (Arvaniti 2007). Neither of these fricatives is part of the Albanian sound system. 
those individuals who were of Albanian origin and who self-reported that spoke both Albanian and Greek, while as ethnically Greek are identified those individuals who were of Greek origin, were born in Greece, and self-reported to be native Greek speakers. In the end, data from a total of 210 individuals were analyzed, 117 of whom were classified as Albanian based on the aforementioned criteria, and the other 93 as Greek. The instructions informed the participants that the stimulus talkers are of Albanian origin to avoid potential associations with speakers of other native or non-native Greek varieties.

Based on the results of a factor analysis, the ruralness and Albanianness perceptions were analyzed individually whereas friendliness, likeability, politeness, and sensibility were collapsed under the same category referred to here as 'likeability'. Similarly, aggressiveness, cursing, and criminality were collapsed under the same category referred to here as 'criminality'. For the statistical analysis of these dependent variables, a set of ordinal mixed effects models were built using the 'ordinal' package (Christensen 2019) for R (R Core Team 2020) with the three-way interaction of variant, word emblematicity, and participant as fixed effects and a maximal design-driven random effects for participants (following Barr et al. 2013), which included a within-subject random intercept and random slopes for variant and word emblematicity.

3. Findings. Overall, there was a significant effect of variant for both of the variables. Talkers producing either one or both of the Albanian Greek variants were perceived as more Albanian $(p<0.001)$, more rural $(p=0.016)$, as less likeable $(p=0.001)$, and more aggressive $(p=0.02)$ than when they were producing the SMG variant. Focusing on the palatal (ç) variant, there was a significant interaction between variant and participant ethnicity for the Albanianness perceptions (Figure 1), and for the ruralness perceptions (Figure 2). For the former, the two Albanian Greek variants, the plosive $[\mathrm{k}]$ and the affricate [cç], were not significantly different from each other for the Albanian participants, but for the Greek participants these were hierarchically ordered, with the talkers who produced the plosive [k] being perceived as more Albanian than those who produced the affricate [çc] variant $(p<0.001)$. As for ruralness perceptions, talkers who produced the Albanian Greek affricate [çc] were perceived as more rural than talkers who produced the Albanian Greek plosive $[\mathrm{k}](p=0.016)$, who in turn were perceived as more rural than those that produced the SMG fricative [ç] $(p<0.001)$. However, the talkers who produced the affricate [ [ç]] were perceived as much more rural than the talkers who produced the plosive $[\mathrm{k}]$ by the Greek listeners more so than by the Albanian listeners $(p=0.025)$.

Turning to the $(\mathrm{x})$ variable, Greek listeners were more likely to perceive talkers as more aggressive than Albanian listeners were, regardless of the variant they produced $(p=0.001)$. For the likeability perceptions, there was, additionally, a significant interaction between variant and participant ethnicity (Figure 3 ). Talkers who produced the SMG fricative [x] were perceived as more likeable by the Albanian listeners than the talkers who produced the Albanian Greek plosive $[\mathrm{k}](p=0.015)$. For the Greek listeners, the two variants were not significantly different from each other although the mean ratings seem to be moving in the opposite direction for the two variants. 


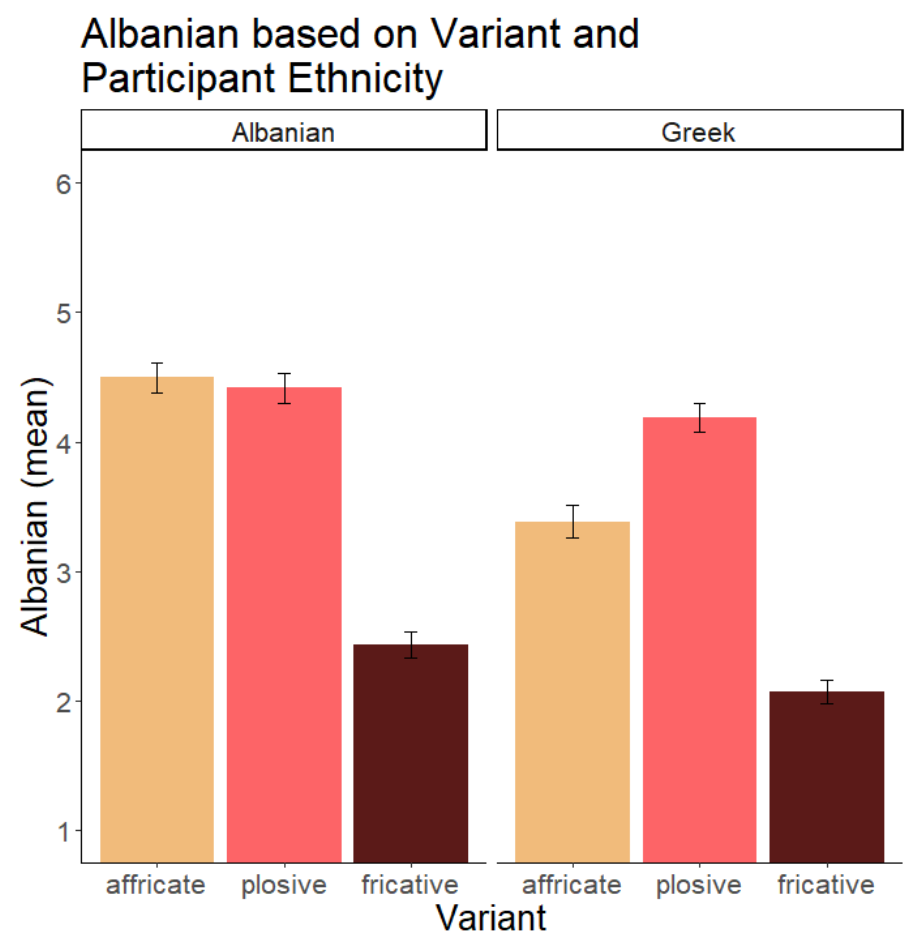

Figure 1. Mean ratings for perceived talker Albanianness for the (ç) words based on variant and participant ethnicity.

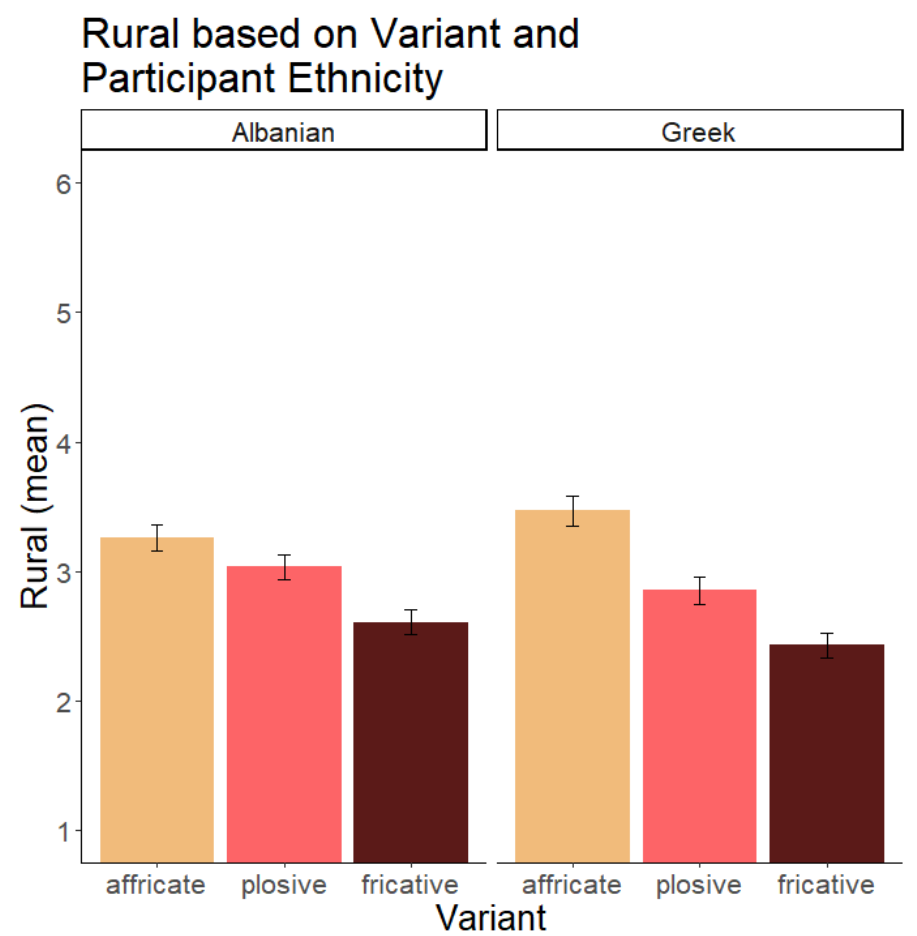

Figure 2. Mean ratings for perceived talker ruralness for the (ç) words based on variant and participant ethnicity. 


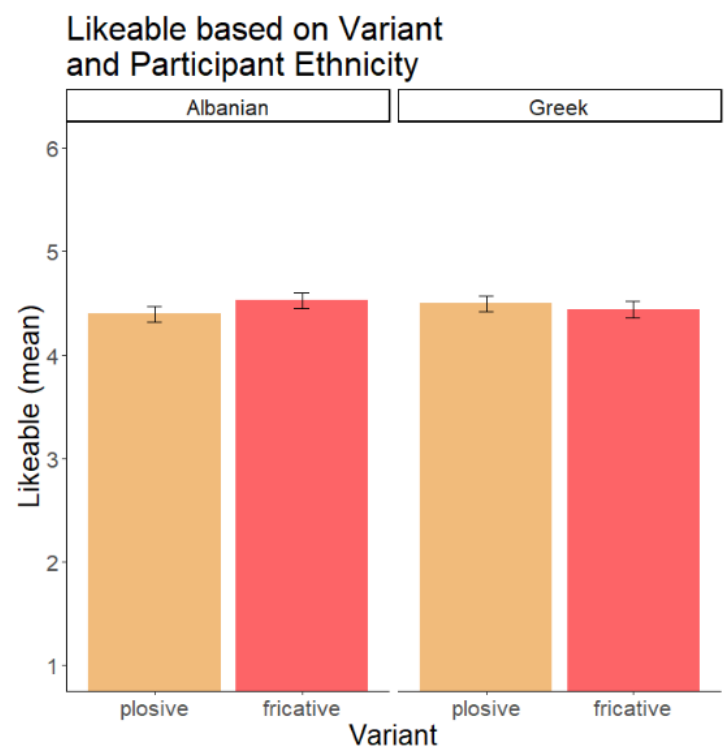

Figure 3. Mean ratings for perceived talker likeability for the (x) words based on variant and participant ethnicity.

4. Discussion and conclusions. From the findings outlined in section 3 , we see that the Albanian Greek variants stigmatize the talkers who produce them to a large extent. Talkers who utter Albanian Greek plosive [k] or affricate[ $\widehat{c c c}]$ instead of SMG [ç] and [x] fricatives lose in likeability while they gain in aggressiveness, ruralness, and Albanianness perceptions. This finding suggests that standard language ideologies (e.g. Milroy \& Milroy 1992, Lippi-Green 1994) might be influencing these perceptions where the standard variant is judged more positively than the nonstandard ethnic variants. Specifically, with regard to Albanianness perceptions, there are some effects that might be motivated by in-group (i.e. Albanians) and out-group (i.e. Greeks) knowledge. Albanians, as members of (or closely affiliated with) the community of the Albanian migrants in Greece, have an insider knowledge of the degrees of proficiency (from heavily accented to fully fluent Greek) that their compatriots have in Greek which means that they are also more likely to accept standard and non-standard speech as a product of their compatriots' output. This in-group and out-group knowledge could further explain why Albanian listeners do not differentiate between the two Albanian Greek variants, whereas Greek listeners evaluate the Albanian Greek plosive [k] as more Albanian than the Albanian Greek affricate [ $\widehat{\mathrm{cc}}]$. Moreover, this difference by listener ethnicity in Albanianness degrees of the non-standard variants could mean that Greek listeners are assigning the most foreign sound (i.e. the plosive $[\mathrm{k}])^{2}$ to the foreign population they have the most contact with (i.e. Albanians). This proposal is reinforced by the fact that two well-known regional Greek varieties, Cretan Greek and Cypriot Greek, have perceptually similar affricates in their systems (Trudgill 2003); ${ }^{3}$ this could explain why the Albanian Greek affricate [ $\widehat{\text { cç] }}$ is viewed as less Albanian than the plosive $[\mathrm{k}]$ by the Greek listeners. In addition, the affricate [ $\overline{\mathrm{cc}}]$ ] is also evaluated as much more rural for Greek listeners than for Albanian listeners, a result which again supports the proposal that this affricate reminds Greeks of the affricates that exist in regional Greek varieties. This is especially true if we take into account that in Greece whatever is not Athenian gets labeled as 'rural' almost by default. ${ }^{4}$

\footnotetext{
${ }^{2}[\mathrm{k}]$ is not foreign in a general sense since it is part of the Modern Greek phonemic inventory. "Foreign" refers here to the non-native realization of the native segment.

${ }^{3}$ Cretan Geek has the alveolo-palatal $[\widehat{t \in}]$ affricate and Cypriot Greek the palato-alveolar $[\widehat{[t}]$ affricate (Trudgill 2003).

${ }^{4}$ Athens is the capital and largest city of Greece and the center of Standard Modern Greek.
} 
Moving to the aggressiveness perceptions, the findings indicate that, regardless of the variant used, Greek listeners perceived talkers as more aggressive than Albanian listeners did. Although the ratings are concentrated at the lower end of the scale (an approximate mean of 2 out of 6), which indicates some attempt in part of the raters at political correctness, we still manage to discern some stigmatization of Albanians as aggressive types of individuals. At the same time, Albanian listeners rate Albanians as less likeable when they produce the Albanian Greek plosive [k] variant than when they produce the SMG fricative [x] variant. It seems, then, that Albanians are covertly penalizing their compatriots who betray their Albanianness through their speech in that they deprive them of likeability rather than more covertly associate them with aggressiveness. This covert penalization might be stemming from some underlying racist ideologies that Albanians could have internalized towards those who have not fully assimilated to the Greek culture to the extent that they are able to produce native-like Greek.

To summarize, I have shown here that Albanian Greek features give rise to standard language ideologies and the stigmatization of Albanians. Talkers who produce such features are perceived as more Albanian and rural, are associated with aggressiveness, and dissociated from likeability, suggesting that this set of associations comprises the indexical field of Albanian Greek features (following Eckert 2008). Furthermore, we saw some overt and covert racist ideologies emerging from Greeks and Albanians respectively. Finally, the findings suggested that there is some differential knowledge among those that are members of the Albanian community in Greece and those that are not. This knowledge differed based on the groups' experience with what constitutes Albanian Greek and Albanians' proficiency levels in Greek, as well as their experience with what constitutes foreign and rural Greek.

Future research should address the potential effects of social networks in perceptions, that is, should examine perceptions of Albanian Greek by individuals that have varying degrees of contact with Albanian migrants (e.g. those with Albanian friends, co-workers, neighbors, employees). Moreover, since this experiment only examined male voices, future work could explore any potential effects of female or non-cisgender voices with relation to the social perceptions of the features described above.

\section{References}

Archakis, Argiris \& Villy Tsakona. 2021. Greek migrant jokes online: A diachronic-comparative study on racist humorous representations. Internet Pragmatics 4(1). 28-51. https://doi.org/10.1075/ip.00063.tsa.

Archakis, Argiris. 2020. The continuum of identities in immigrant students' narratives in Greece. Narrative Inquiry Online first. https://doi.org/10.1075/ni.19118.arc.

Arvaniti, Amalia, 2007. Greek phonetics: The state of the art. Journal of Greek Linguistics 8. 97-208. https://doi.org/10.1075/jgl.8.08arv.

Barr, Dale J., Roger Levy, Christoph Scheepers \& Harry J. Tily. 2013. Random effects structure for confirmatory hypothesis testing: Keep it maximal. Journal of Memory and Language 68. 255-278. https://doi.org/10.1016/j.jml.2012.11.001.

Christensen, Rune H. B. 2019. Ordinal: Regression Models for Ordinal Data. https://CRAN.Rproject.org $/$ package $=$ ordinal.

Eckert, Penelope. 2008. Variation and the indexical field. Journal of Sociolinguistics 12(4). 453-476. https://doi.org/10.1111/j.1467-9841.2008.00374.x.

Hellenic Statistical Authority. 2014. 2011 Population and Housing Census. LINK.

Lazaridis, Gabriella \& Eugenia Wickens. 1999. "Us" and the "others": Ethnic minorities in Greece. Annals of Tourism Research 26(3). 632-655. https://doi.org/10.1016/S01607383(99)00008-0.

Lippi-Green, Rosina.1994. Accent, standard language ideology, and discriminatory pretext in the courts. Language in Society 23(2). 163-198. http://www.jstor.org/stable/4168513. 
Mai, Nicola \& Stephanie Schwandner-Sievers. 2003. Albanian migration and new transnationalisms. Journal of Ethnic and Migration Studies 29(6). 939-948. https://doi.org/10.1080/1369183032000171302.

Milroy, James \& Lesley Milroy.1992. Authority in language: Investigating language prescription and standardization. London: Routledge.

Ndoci, Rexhina. Forthcoming a. Albanian immigrants in Greece and what they meme.

Ndoci, Rexhina. Forthcoming b. Listener ethnicity and word emblematicity in the perception of Albanian Greek.

Ndoci, Rexhina. 2021. Social perceptions of Albanian Greek. Columbus, OH: The Ohio State University qualifying paper.

R Core Team. 2020. R: A Language and Environment for Statistical Computing. Vienna, Austria. https://www.R-project.org/.

Trudgill, Peter. 2003. Modern Greek dialects: A preliminary classification. Journal of Greek Linguistics 4. 45-64. https://doi.org/10.1075/jgl.4.04tru. 